\title{
Mendenhall's syndrome: clues to the aetiology of human diabetic neuropathy
}

\author{
Rayaz A Malik, Sudhesh Kumar, Andrew J M Boulton
}

\begin{abstract}
The pathogenesis of human diabetic neuropathy remains unclear. Mendenhall's syndrome is characterised by a mutation in the insulin receptor gene with consequent lifelong uncontrolled hyperglycaemia. The sural nerve biopsy from a patient with Mendenhall's syndrome showed a gross loss of myelinated fibres that was comparable with the degree of fibre loss in a case matched diabetic patient with established neuropathy. The biopsy from the patient with Mendenhall's syndrome showed only a very mild degree of microangiopathy, however, which failed to relate to the degree of nerve fibre loss and also did not compare with the advanced degree of microangiopathy seen in the diabetic patient. Thus hyperglycaemia itself did not result in appreciable microangiopathy. Furthermore the presence of severe neuropathy without advanced microangiopathy suggests an important and independent role for metabolic factors in the pathogenesis of neuropathy.
\end{abstract}

$(\mathcal{F}$ Neurol Neurosurg Psychiatry 1995;58:493-495)

Keywords: hyperglycaemia; neuropathy; microangiopathy

Diabetic peripheral neuropathy is the most common cause of neuropathy in industrialised countries and is a cause of very high morbidity and mortality in diabetic patients. Its pathogenesis, however, remains unclear. ${ }^{2}$ The results of the recently completed Diabetes Control and Complications Trial clearly show that glycaemic control is extremely important in both preventing the development and in delaying progression of neuropathy, retinopathy, and nephropathy. ${ }^{3}$ Evidence now also suggests that microvascular disease plays an equally important part in the pathogenesis of neuropathy. ${ }^{4}$ It is unclear, however, as to whether advanced neuropathy develops directly via hyperglycaemia or whether it develops secondary to microangiopathy. Mendenhall's syndrome is a rare genetic syndrome with extreme insulin resistance due to a defect in the $a$ subunit of the insulin receptor ${ }^{5}$ resulting in lifelong uncontrolled hyperglycaemia, with a propensity to develop neuropathy, retinopathy, and nephropathy, leading ultimately to death at an early age. ${ }^{6}$ We have had the unique opportunity to study the peripheral nerve pathology in one such patient to gain insight into the role of prolonged uncontrolled hyperglycaemia in the pathogenesis of microangiopathy and also the relative contributions of metabolic and microvascular factors in the pathogenesis of neuropathy.

\section{Patients and methods}

The sural nerve was biopsied from a 24 year old male patient with Mendenhall's syndrome, one of the longest recorded surviving cases. ${ }^{7} \mathrm{He}$ had uncontrolled lifelong hyperglycaemia (all random blood glucose $>21$ $\mathrm{mmol} / \mathrm{l}$; HbAlc $16 \cdot 1 \%$, normal $<8 \%$ ) with resultant blindness from proliferative retinopathy, proteinuria $(1 \mathrm{~g} / 24 \mathrm{~h})$, and gross neuropathy with foot ulceration and gangrene necessitating a left below knee amputation (biopsy performed immediately before the amputation). For morphological comparison a sural nerve biopsy was also obtained from an insulin dependent diabetic patient roughly matched for duration of diabetes (21 years) and severity of neuropathy and an age (24 years) matched control subject (renal transplant donor). Although functional assessment of endoneurial blood flow and oxygenation are clearly the most relevant parameters they could not be assessed due to the clinical circumstances under which the biopsy was taken (before amputation). The biopsies were processed for detailed light and electron microscopic morphometry. ${ }^{8-10}$ Mean fascicular area, and myelinated fibre and endoneurial capillary density were determined directly from all fascicles ( $>6 /$ biopsy) found in semithin sections. Electron micrographs of endoneurial capillaries ( $>10 /$ biopsy) were prepared from ultra-thin sections and parameters (basement membrane area, luminal area, endothelial cell area, and profile number) that constitute the hallmarks of diabetic microangiopathy were analysed by employing manual digitisation according to previously described morphometric techniques. ${ }^{910}$

\section{Results}

All three nerve biopsies contained no amyloid deposit, and no evidence of vasculitis or inflammatory infiltrate suggestive of any other 
Nerve fibre and endoneurial capillary pathology in the sural nerve biopsy of the study patients expressed as real numbers and percentages of control subject

\begin{tabular}{|c|c|c|c|}
\hline Sural nerve pathology & Control & Diabetic & Mendenhall's \\
\hline $\begin{array}{l}\text { Myelinated fibre density }\left(\mathrm{No} / \mathrm{mm}^{2}\right) \\
\text { Fascicular area }\left(\mathrm{mm}^{2}\right) \\
\text { Capillary density }\left(\mathrm{No} / \mathrm{mm}^{2}\right) \\
\text { Basement membrane area }\left(\mu \mathrm{m}^{2}\right) \\
\text { Endothelial cell area }\left(\mu \mathrm{m}^{2}\right) \\
\text { Endothelial cell profile No }\end{array}$ & $\begin{array}{c}6820 \\
0 \cdot 08 \\
75 \cdot 7 \\
55 \cdot 06 \\
41 \cdot 9 \\
4 \cdot 1\end{array}$ & $\begin{array}{l}823(12 \cdot 1) \\
0 \cdot 15(187 \cdot 5) \\
36 \cdot 3(47 \cdot 9) \\
318 \cdot 0(577 \cdot 6) \\
45 \cdot 7(109 \cdot 1) \\
7 \cdot 2(175 \cdot 6)\end{array}$ & $\begin{array}{r}1175(17 \cdot 2) \\
0.07(87 \cdot 5) \\
84 \cdot 3(111 \cdot 4) \\
117 \cdot 7(213 \cdot 8) \\
42 \cdot 9(102 \cdot 4) \\
5.5(134 \cdot 1)\end{array}$ \\
\hline
\end{tabular}
Light $(\times 275)$ and electron representative fascicles and endoneurial capillaries respectively from the sural nerve of the patient with Mendenhall's syndrome. These show gross loss of myelinated fibres ( $m f)(A)$ and mild microangiopathy (a) compared with the matched diabetic patient with a comparable loss of myelinated fibres (B) but pronounced thickening of basement membrane (bm) confirming severe microangiopathy (b). Normal myelinated fibre density (C) and endoneurial capillary (c) are shown from the control subject.

cause of neuropathy. The patient with Mendenhall's syndrome had a much reduced findings in the diabetic patient and this was considerably less than in the control subject (table, figure). With regard to evidence of microangiopathy, there was no evidence of endoneurial oedema as assessed by mean fascicular area or a reduction in capillary density myelinated fibre density comparable with our
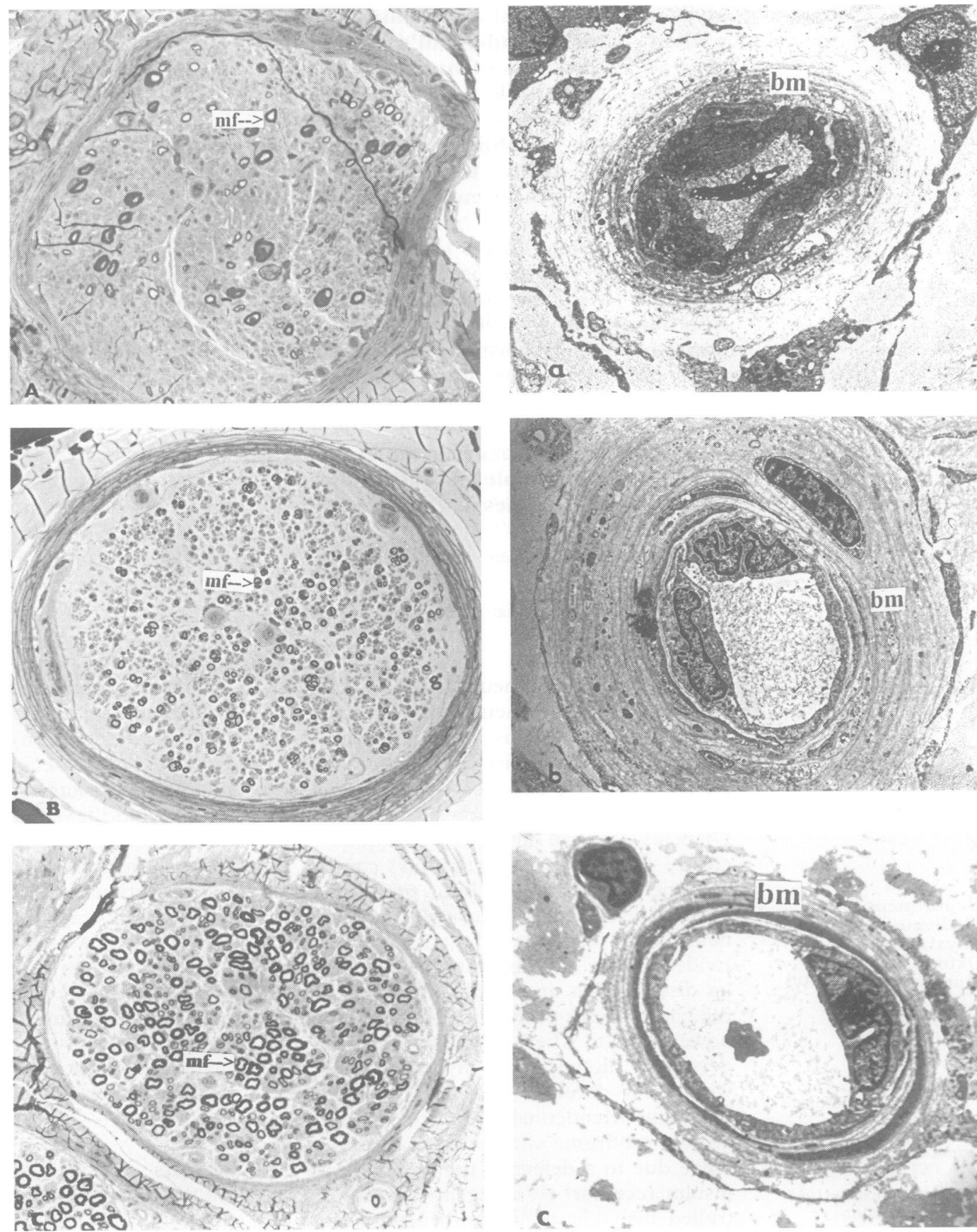

in the patient with Mendenhall's syndrome. Endoneurial capillaries showed a marginal increase in basement membrane area, endothelial cell profile number, and endothelial cell area in the patient with Mendenhall's syndrome. The diabetic patient had a twofold increase in mean fascicular area, indicative of endoneurial oedema and an associated reduction in endoneurial capillary density. Furthermore, there was also a considerable increase in basement membrane area and endothelial cell profile number indicative of microvascular matrix and cellular hyperplasia. Thus the degree of microangiopathy in the patient with Mendenhall's syndrome was very mild and did not relate to the degree of myelinated fibre loss. This was by contrast with the severe microangiopathy and associated nerve fibre loss in our diabetic patient (table, figure). 


\section{Discussion}

Considerable debate exists regarding the relative importance of metabolic and microvascular factors in the pathogenesis of human diabetic neuropathy. ${ }^{2}$ There is much evidence in favour of a metabolic basis for the pathogenesis of this condition. ${ }^{23}$ Equally, microangiopathy and hence hypoxia have been considered to have an important and perhaps decisive role in the development of neuropathy as they do in the development of both retinopathy and nephropathy. ${ }^{24}$ Microangiopathy has of course been considered to be a direct consequence of hyperglycaemia. Although broad conclusions cannot be drawn from a single case, this study does provide some important insights into the possible mechanisms for the development of both diabetic microangiopathy and neuropathy. This detailed pathological study of the sural nerve in a patient with Mendenhall's syndrome and hence lifelong hyperglycaemia ${ }^{7}$ shows severe nerve fibre loss consistent with the clinical findings of a diffuse peripheral sensorimotor neuropathy, which resulted in neuropathic ulceration and eventual lower limb amputation. ${ }^{8-10}$ We failed, however, to show severe microangiopathy, characterised by endoneurial oedema and consequent reduction in capillary density, basement membrane thickening, and endothelial cell hypertrophy and hyperplasia. This was the type of endoneurial microangiopathy found in our case matched diabetic patient and indeed other diabetic patients..$^{910}$ Thus severe prolonged hyperglycaemia does not necessarily result in diabetic microangiopathy and therefore factors other than the effects of hyperglycaemia alone should be sought to explain the development and progression of microangiopathy in diabetic patients. Hyperinsulinaemia has of course been implicated in proliferation of arterial wall smooth muscle and also in atherogenesis. Surprisingly, however, our patient with Mendenhall's syndrome who had overt hyperinsulinaemia showed a lesser proliferative effect of either endothelial cells or basement membrane than the diabetic patient who would clearly be expected to be hypoinsulinaemic. This difference in proliferative response may simply be related to the smaller vessels studied as arterioles and arteries were not examined. The presence of a severe clinical neuropathy evidenced by the development of foot ulceration, gangrene, and eventual lower limb amputation and pronounced fibre loss in the absence of a comparably pronounced microangiopathy, ${ }^{10}$ suggests that if metabolic factors are severe enough, as they were in our patient with Mendenhall's syndrome; then they alone may have an independent and important role in the pathogenesis of human diabetic neuropathy.

1 Reiber GE. Epidemiology of the diabetic foot. In: Levin $\mathrm{ME}$, O'Neal LW, Bowker JH, eds. The diabetic foot. 5th ed. St Louis Mosby-Year Book Inc, 1993:1-15.

2 Boulton AJM. Pathogenesis of diabetic neuropathy. In Marshall SM, Home PD, Alberti KGMM, Krall LP. eds. The diabetes annual/7. Amsterdam: Elsevier, 1993:192-210.

3 The Diabetes Control and Complications Trial Research Group. The effect of intensive treatment of diabetes on the development and progression of long term complithe development and progression of long term compliMed 1993;329:977-986.

4 Tesfaye S, Malik RA, Ward JD. Vascular factors in diabetic neuropathy. Diabetologia 1994;37:847-54.

5 Krook A, Kumar S, Laing I, Boulton AJM, Wass JAH, O'Rahilly SP. Molecular scanning of the insulin receptor gene in syndromes of insulin resistance. Diabetes 1994;43:357-68.

6 O'Rahilly S, Moller DE. Mutant insulin receptors in syndromes of insulin resistance. Clin Edocrinol (Oxf) 1992 36:121-32.

7 Kumar S, Boulton AJM. Serious, prolonged hypoglycaemia with glibenclamide in a patient with Mendenhall's syndrome. Clin Endocrinol (Oxf) 1993;39. 109-11.

8 Britland ST, Young RJ, Sharma AK, Clarke BF. Association of painful and painless diabetic polyneuropathy with different patterns of nerve fibre degeneraropathy with different patterns of nerve fibre degen

9 Malik RA, Newrick PG, Sharma AK, Jennings A, Ah-See AK, Mayhew TM, et al. Microangiopathy in human diabetic neuropathy: relationship between capillary abnormalities and the severity of neuropathy Diabetologia 1989;32:92-102.

10 Malik RA, Veves A, Masson EA, Sharma AK, Ah-See AK, Schady W, et al. Endoneurial capillary abnormalities in mild human diabetic neuropathy. 7 Neurol Neurosurg Psychiatry 1992;55:557-61. 